NBER WORKING PAPER SERIES

\title{
OPTIMAL DRUG POLICY IN LOW-INCOME NEIGHBORHOODS
}

\author{
Sheng-Wen Chang \\ N. Edward Coulson \\ Ping Wang \\ Working Paper 9248 \\ http://www.nber.org/papers/w9248 \\ NATIONAL BUREAU OF ECONOMIC RESEARCH \\ 1050 Massachusetts Avenue \\ Cambridge, MA 02138 \\ October 2002
}

We acknowledge the helpful comments of Marcus Berliant, Eric Bond, John Conley, Bob Helsley, Derek Laing, Wan-Shiang Pan, Jennifer Reinganum, KojiShimomura, Norm Skoufias, Will Strange, Alison Watts and participants at Kobe, Southern Illinois, Vanderbilt, Washinton (St. Louis), the Regional Science Association International Meetings in Chicago, the International Conference on Public Economics in Taipei, and the Midwest Economic Theory Meetings at Minnesota. The third author acknowledges financial support from NIH/NIAAA grant no. 1R01-AA11657-01,02. The views expressed herein are those of the authors and not necessarily those of the National Bureau of Economic Research.

(C) 2002 by Sheng-Wen Chang, N. Edward Coulson and Ping Wang. All rights reserved. Short sections of text, not to exceed two paragraphs, may be quoted without explicit permission provided that full credit, including $\odot$ notice, is given to the source. 
Optimal Drug Policy in Low-Income Neighborhoods

Sheng-Wen Chang, N. Edward Coulson and Ping Wang

NBER Working Paper No. 9248

October 2002

JEL No. D60, J60, K42, H70

\section{$\underline{\text { ABSTRACT }}$}

Part of the debate over the control of drug activity in cities is concerned with the effectiveness of implementing demand- versus supply-side drug policies. This paper is motivated by the relative lack of research providing formal economic underpinning for the implementation of either policy. We construct a simple model of drug activity, in which the drug price and the distribution of population in a community are determined according to a career choice rule and a predetermined drug demand. Three potential government objectives are considered. We find that both demand- and supply-side policies have theoretical support under different community conditions. While the demand-side policy discourages active drug sellers, the supply-side policy has an additional drug-dealing replacement effect on inducing potential entry of drug dealers. In lowincome neighborhoods, demand-side policy is more effective if the drug problem is more sever or if the government objective is to deter dealer entry or to promote community's aggregate income rather than minimizing active drug selling.

$\begin{array}{lll}\text { Sheng-Wen Chang } & \text { N. Edward Coulson } & \text { Ping Wang } \\ \text { Department of Public Finance } & \text { Department of Economics } & \text { Department of Economics } \\ \text { National Chengchi University } & \text { Penn State University } & \text { Vanderbilt University } \\ \text { Taipei, Taiwan 11623 } & \text { University Park, PA 16802 } & \text { Nashville, TN 37235 } \\ \text { R.O.C. } & \text { U.S.A. } & \text { U.S.A. } \\ \text { sxc240@nccu.edu.tw } & \text { fyj@psu.edu } & \text { and NBER } \\ & & \text { ping.wang@vanderbilt.edu }\end{array}$




\section{Introduction}

While by some measures drug use and trafficking have declined in recent years, these issues continue to be of significant and increasing social concern in the U.S. Evidence of this comes from the fact that spending on all forms of drug control by the U.S. government has increased over $25 \%$ in real terms between 1992 and 1999, reaching, by the latter date, 17.8 billion dollars. ${ }^{1}$ Of this amount, very nearly half ( $\$ 8.7$ billion) was spending on the arrest and prosecution of domestic drug control offenders. Those who are arrested and prosecuted can be segmented into two broad categories: those arrested for the sale and/or manufacture of drugs, and those arrested for possession. Although not exactly accurate, ${ }^{2}$ we will, for convenience, characterize these two types of arrests as supply-side and demand-side arrests, and efforts to concentrate on one type of arrest or another as supply- or demand-side policies.

The mix of supply-side and demand-side policy has shifted over the years. Figure 1 plots supply-side arrests as a percentage of total arrests by all U.S. law enforcement agencies from 1988 through 1997 . While the number of total arrests increased fairly steadily through this period (from about 1.15 million to about 1.58 million) the percentage of arrests that were for supply-side violations rose from 28\% in 1988 to about one-third in 1991 and then dropped dramatically to about one-fifth of total arrests by 1997. Demand-side policies generally have their critics - indeed the whole notion of a "drug war" is broadly criticized-- but some scholars have advocated policies more oriented toward the demand-side in place of supply-side oriented policies. Among these is Meares (1998) who recommends the so-called "reverse sting"

\footnotetext{
${ }^{1}$ The rates of increase were even more rapid in the 1980s. These figures and the ones that follow are from National Office of Drug Control Policy (1999)

${ }^{2}$ More specifically, someone might be, for example, arrested and/or prosecuted and/or pleabargained for possession even though the intent of the possessor was the eventual sale of the drugs.
} 
operation, where law enforcement officials pose as drug sellers in order to gather evidence on buyers, rather than the usual method of posing as buyers to arrest dealers. Meares emphasizes the positive effect that this may have on inner-city communities. While not denying that inner city neighborhoods can be the site of active markets in illegal drugs, perhaps as many as $80 \%$ of drug buyers come from outside the market-neighborhoods. ${ }^{3}$ The emphasis on supply-side policy therefore has a disproportionate effect on those low-income areas of a community that are often the site of drug markets, which can have an aggravating impact on its law-abiding residents.

We formally examine the effects of supply and demand side policy, emphasizing that these policies have different impacts on the price of drugs and therefore on the incentives of those on the margin between the drug and legitimate labor markets. The basic idea is simple. A supply-side policy that reduces (at least temporarily) the number of sellers may drive up the price of the drug and so provide incentives for those previously employed in the legitimate labor market to take up drug-selling. ${ }^{4}$ A demand-side policy, conversely, drives down the number of demanders and the price, which provides an incentive for dealers to enter the legitimate market. Thus, supply-side policy drains the local neighborhood of its resources without necessarily reducing drug traffic, while the demand-side policy reduces drug traffic without the negative side effect. This side effect is magnified when the low-income community must pay for its own law enforcement activities.

\footnotetext{
${ }^{3}$ Rosen's (1997) discussion of drug markets in Chicago indicates that almost $80 \%$ of the drug buyers come from outside the inner-city neighborhood $\mathrm{s}$ where the exchanges took place. ${ }^{4}$ In this regard, our analysis could be applied to a number of illegal commodities. We focus on illegal drugs because of their policy importance.
} 
We propose, to our knowledge for the first time, an analytical model capable of analyzing the consequences of both demand-side and supply-side drug policies and comparing the welfare of these policies in a way similar to the general-equilibrium tax incidence framework. We follow the standard set by Becker (1968) in assuming optimizing behavior on the part of (potential and active) participants in illegal activities. Residents of a neighborhood have the choice of participating in the legitimate labor market or engaging in the drug trade. The structure of the legitimate labor market is much simplified with an exogenous wage matched with a search and matching framework in the style of Diamond (1982). The drug trade is, however, modeled in some detail. The drug market is cleared in the usual supply-and-demand fashion, while the entry of sellers continues until reaching ex ante zero profit, in the style of the labor-matching framework developed by Laing, Palivos and Wang (1995) and Coulson, Laing and Wang (2001). The extent to which community members opt for a career in the drug market determines the supply of drugs by the community. As noted above, we assume that demand for drugs is exogenous to the community. Drug demand is assumed to be downward-sloping (Chaloupka, Grossman and Tauras (1999)) . The community government, by incurring law enforcement spending, can determine the optimal arrest/release rates of not only drug suppliers but drug demanders. To a large degree, the arrest and release rates, respectively, can be regarded as a tax on and a subsidy to participants in illegal activities. Something like the conventional tax incidence framework can thus be applied to evaluation of demand-side versus supply-side drug policies.

Therefore, the central features of our paper are to consider (i) endogenous demand/supply of drugs and active trading prices, (ii) individually optimizing career choice between legitimate and illegitimate activities, and (iii) the community government's exercises in incarcerating drug 
suppliers and demanders. Specifically, the participants in the drug market may be active or incarcerated, depending on the arrest and release rate chosen by the local community government, whose point of view we choose ${ }^{5}$. We derive value functions for each occupation, based on legitimate labor market payoffs as well as expected returns on drug sales. Endogenous career choice and drug market equilibrium together determine the price and the actively traded quantity of drugs. Since the release rates within our analytical framework are simply mirror images of the arrest rates, we focus on examining the effects of the rates at which drug demanders and suppliers are incarcerated. In assessing these drug policies, we consider an array of plausible community objectives with regard to reducing drug activity and improving the standard of living, and explicitly account for the law enforcement spending that is financed by a tax on legitimate labor income.

We find that the relative effectiveness of demand-side versus supply-side policies depends crucially on the objective of the local government as well as the drug demand schedule. Under a linear drug demand schedule, the demand arrest policy is likely to be more effective due to the asymmetric effects of demand- and supply-side policies on drug contact rates and equilibrium prices. This is so especially when the two arrest policies have identical effects on the amount of spending by law enforcement agencies. Compared to the objective of minimizing active drug selling, deterrence of dealer entry results in a relatively lower optimal supplier arrest rate while promotion of community's aggregate income leads to lower levels of both optimal drug arrest policies. Under a constant-elasticity drug demand schedule, the main conclusions concerning various local government objectives remain qualitatively unchanged. Nevertheless,

\footnotetext{
${ }^{5}$ We consider the choice of optimal policy strictly from the point of view of low -income community in which the sellers live and transactions take place. Thus we do not consider the effect that these policies might have on the larger community.
} 
the price elasticity of drug demand becomes a crucial determinant for the welfare comparison between demand and supply policies. In areas with severe drug problems in the sense that drug demand is price-inelastic, the demand-side arrest policy is more effective, which is similar to well-known properties of the optimal taxation literature in a very different context.

In Section 2 we lay out the model basics, using the search-and-match framework in the legitimate labor market and derive the drug price offer function based on the career choice decision. The steady-state equilibrium is then defined and characterized in Section 3, in which equilibrium drug prices and actively traded quantities as well as the comparative static results with respect to changes in labor market factors and drug arrest policies are subsequently

presented. In Section 4, we examine the effectiveness of drug demand and supply policies given a balanced government budget under two (linear and constant elasticity) drug demand setups and various welfare objectives. We provide an array of interesting extensions of the basic model in Section 5 and, finally, conclude the paper in Section 6 with a remark on possible avenues for future research.

\section{The Economic Environment of the Community}

This section describes the basic economic environment for a local community. We utilize a continuous-time search and matching framework, in which the community is populated by a continuum of identical agents, each possessing the instantaneous discount rate over consumption of $r>0$. The agents in this community are engaged in one of two economic activities. One is the legitimate labor market in which community members and unfilled vacancies are brought together via a stochastic matching technology in the background. The other is the drug market in which dealers living in this community provide illegal drugs for outside demanders. All agents are endowed with one unit of labor that they can either supply to 
firms or devote to drug selling (without disutility from effort). Due to law enforcement, participants in the drug activity (both suppliers and demanders) may be active or incarcerated.

The search and matching framework captures the presence of informational incompleteness regarding the identification of drug demanders and suppliers. Moreover, it provides a parsimonious structure for our policy analysis because both arrest and release rates can be modeled as Poisson arrival parameters, which greatly simplify the specifications of value functions (Bellman equations). In the benchmark setup, we abstract the interactive externality from drug dealing and ignore the utility cost of incarceration and the social cost of drugs. Additionally, we assume that each dealer at a point in time possesses only one unit of drug for sale. These assumptions will all be relaxed in Section 5 .

\section{Population}

Denote the population of workers as $N$ and the population of drug dealers as $Q$. We employ the population identity

$$
N+Q=1 .
$$

Within the labor market workers may be either employed or unemployed and, similarly, drug dealers may be either active or incarcerated. Denote the population of employed and unemployed workers, and active and incarcerated drug dealers as $L, U, A$ and $I$, respectively. The two sub-group population identities are $N=L+U$ and $Q=A+I .{ }^{6}$

\section{Labor Market}

In the labor market, firms provide job vacancies for workers. Once residents have made their career choices to become workers, they enter the labor market as unemployed and search for employment. Searching workers and unfilled vacancies are brought together via a stochastic

\footnotetext{
${ }^{6}$ Since total population is unity, all "populations" can be interpreted as "percentages".
} 
matching technology. Once employed, each worker produces 1 unit of output (by normalization), of which some fraction w accrues to the worker. We call this the wage of the worker. Since the formal labor market is not the focus of the paper, the process of Nash bargain in determining this share is neglected for brevity. ${ }^{7}$ Obviously, a higher output enlarges the entire surplus from a match and so the wage increases.

In the labor market, there are turnovers in existing jobs. Firms lay off workers at a constant rate, $\delta$. In the steady state the inflows and outflows into and out of employment must be the same:

$$
\mu U=\delta L
$$

where $\mu$ is the rate at which unemployed workers are able to contact firms.

\section{Drug Market}

As noted, we regard the community as a "small open" economy in the sense that all drug demanders come from outside the community. That is, the total population of drug demanders, denoted by $Q_{d}$, is predetermined in our model. However some are incarcerated and some are active. Let $A_{d}$ and $I_{d}$, respectively, denote the population of active and incarcerated drug demanders respectively (throughout, the subscript $d$ represents demanders and $s$, suppliers). The population identity requires: $A_{d}+I_{d}=Q_{d}$.

The demand for drugs is a function of its price and the number of active drug demanders. In addition, we assume that the drug demand schedule is downward-sloping (Chaloupka, Grossman and Tauras, 1999) and satisfies the usual regularity conditions:

\footnotetext{
${ }^{7}$ We have formally examined such a framework - it leads to no qualitative changes in our main findings concerning the effectiveness of drug policies.
} 
Assumption 2. (Drug Demand) The aggregate drug demand function, $D: \boldsymbol{R}_{+}{ }^{2} \rightarrow \boldsymbol{R}_{+}$, is strictly decreasing, convex and twice continuously differentiable in $p$, and strictly increasing in $A_{d}$, i.e., $\partial D / \partial p<0, \partial^{2} D / \partial p^{2} \geq 0$ and $\partial D / \partial A_{d}>0$.

Each agent who chooses to become a dealer is endowed with a single unit of drugs. ${ }^{8}$ As long as we consider linear drug pricing, this simplifying assumption is innocuous with regard to price determination. In this case, the total supply of drugs depends only on the number of active dealers, $A_{s}$, where all dealers are identical ex ante. (Ex post some may be active and others be incarcerated.) In equilibrium, it is required that supply equals demand:

$$
A_{s}=S=D\left(p, A_{d}\right)
$$

The drug price, $p$, satisfies a no-arbitrage condition for the career choice between drug dealing and working in the legitimate labor market (to be determined below) and the equilibrium condition in the drug market described as in (3).

We assume drug dealers are arrested and released at constant rates, $\tau_{s}$ and $\rho_{s}$. In the steady state, the outflow from the pool of active drug dealers (i.e., those arrested) must be equal to the inflow (i.e., those released from jail):

$$
\tau_{s} A_{s}=\rho_{s} I_{s}
$$

Similarly, as drug demanders are arrested and released at constant rates, $\tau_{d}$ and $\rho_{d}$, the steady state requires:

$$
\tau_{d} A_{d}=\rho_{d} I_{d}
$$

\footnotetext{
${ }^{8}$ In making this simplifying assumption we ignore the interesting industrial organization of the illicit drug market (Levitt and Venkatesh (2000)). By assuming that dealers are endowed with their supply, we are eschewing analysis of policies, such as increased monitoring by customs officials, directed at affecting the dealer's price of drugs.
} 
This completes the description of the structure of the local economy - see Chart 1 for a diagrammatic illustration.

\section{Value Functions and Drug Price Offer Function}

Now we are able to describe the expected returns of workers and drug dealers by applying standard dynamic programming techniques. ${ }^{9}$ We first define the flow values for each agent. Define $J_{i}\left(i=L, U, A_{s}, I_{s}\right)$ as the (lifetime) value functions for each of the types of residents. Then the Bellman equations specifying these asset values are given by, ${ }^{10}$

$$
\begin{aligned}
& r J_{L}=w+\delta\left(J_{U}-J_{L}\right) \\
& r J_{U}=\mu\left(J_{L}-J_{U}\right) \\
& r J_{A s}=p+\tau_{s}\left(J_{I s}-J_{A S}\right) \\
& r J_{I S}=\rho_{S}\left(J_{A s}-J_{I S}\right)
\end{aligned}
$$

These equations have standard interpretations. For example, $(6 \mathrm{c})$ indicates that the flow value of an active drug dealer is the sum of the flow revenue from selling one unit of drug and the flow value from changing the state (from active to incarcerated). From equations (6a-d), the asset values related to workers and criminals can be written as functions of the wage rate or drug price:

$$
\begin{aligned}
& J_{L}=\frac{r+\mu}{r+\delta+\mu} \frac{w}{r} \\
& \mathrm{~J}_{\mathrm{U}}=\frac{\mu}{\mathrm{r}+\delta+\mu} \frac{\mathrm{w}}{\mathrm{r}}
\end{aligned}
$$

\footnotetext{
${ }^{9}$ The welfare of firms is not essential to our analysis and, from the community's point of view, the welfare of the outside drug demanders is not the concern. Both firm owners and drug demanders are ignored here.

${ }^{10}$ The instantaneous utility for employed workers is the wage $w$, and for dealers it is the price of drugs, $p$. Both unemployed workers and prisoners have utility of zero, but see below.
} 


$$
\begin{aligned}
& J_{A s}=\frac{r+\rho_{s}}{r+\rho_{s}+\tau_{s}} \frac{p}{r} \\
& J_{I s}=\frac{\rho_{s}}{r+\rho_{s}+\tau_{s}} \frac{p}{r}
\end{aligned}
$$

We now turn to the determination of the drug supply function. We assume that all career-choice decisions are made instantaneously according to a career-choice rule, so that the two careers provide equal expected values in equilibrium. That is,

$$
J_{U}=J_{A s}>0 .
$$

When residents face their career choices, they treat wage as given as in (1). Using (6) and (8), we can derive the drug supply function, which turns out to be a linear function of wage and is perfectly elastic: $\mathrm{p}\left(\mathrm{w}, \mu, \delta, \mathrm{r}, \tau_{\mathrm{s}}, \rho_{\mathrm{s}}\right)=\frac{\mu}{\mathrm{r}+\mu+\delta} \frac{\mathrm{r}+\rho_{\mathrm{s}}+\tau_{\mathrm{s}}}{\mathrm{r}+\rho_{\mathrm{s}}} \mathrm{w} .{ }^{11} \quad$ The perfectly elastic drug supply suggests drug dealers are price takers. Once the wage has been given, the career-choice rule and the equilibrium condition suggest the drug price will be set so that both Eqs. (9) and (3) hold. The drug market is cleared through the adjustment of distribution of population (in the community) only.

For any given value of $r$, let $p\left(w, \mu, \delta, \tau_{s}, \rho_{s}\right)$ denote the drug price offer function. We then have,

Proposition 1. (Drug Price Offer Function) Given the wage function specified as in (1), the drug price offer function, $p\left(w, \mu, \delta, \tau_{s}, \rho_{s}\right)$, determined by the career choice rule (8) and by the drug market equilibrium condition (3), is given by:

$$
p\left(w, \mu, \delta, r, \tau_{s}, \rho_{s}\right)=\frac{\mu}{r+\delta+\mu} \frac{r+\rho_{s}+\tau_{s}}{r+\rho_{s}} w,
$$

${ }^{11}$ For a positive sloped drug supply, the drug price function is determined by both the career choice rule and the equilibrium condition. Therefore, the drug demand plays a role in determining drug price (see Section 5). 
satisfying: $\partial p / \partial w>0, \partial p / \partial \mu>0, \partial p / \partial \delta<0, \partial p / \partial \tau_{s}>0$, and $\partial p / \partial \rho_{s}<0$.

The comparative static properties of $p\left(\mathrm{w}, \mu, \delta, \tau_{s}, \rho_{s}\right)$ have intuitive interpretations. Since the drug price is a linear function of the wage rate, an increase in the wage (through increases in productivity or the share of output accruing to labor) will increase (expected) asset values of workers, and consequently will raise the drug price (proportionately) to keep the two career values the same. A more frequent matching rate of workers with vacancies, $\mu$, makes alternative options more accessible to workers, thereby raising the asset values of workers and the drug price. A high layoff rate, $\delta$, lowers the asset values of workers and therefore the drug price.

Two properties related to the drug market parameters are worthy of special attention. Given the career choice rule, an increase in the supply-side arrest rate, $\tau_{s}$, lowers the expected value of being drug dealers and consequently raises the drug price. In contrast to the arrest rate, an increase in the supply-side release rate, $\rho_{s}$, raises the expected value of being a drug dealer and lowers the drug price. Importantly, it should be noticed that neither the arrest nor the release rates for drug demanders affect the drug price offer function.

\section{Steady-State Equilibrium}

To begin, consider the following:

Definition 1. A steady-state equilibrium is a wage $w$, a drug price function $p\left(\mathrm{w}, \mu, \delta, \tau_{s}, \rho_{s}\right)$, and an list of populations $\left(A_{d}{ }^{*}, I_{d}{ }^{*}, A_{s}{ }^{*}, I_{s}{ }^{*}, Q_{s}{ }^{*}, N^{*}, L^{*}, U^{*}\right)$ satisfying the following conditions:

(i) (Career Choice): (8);

(ii) (Drug market equilibrium): (3);

(iii) (Steady state): (2), (4) and (5);

(iv) (Population identities):

$$
\begin{aligned}
& N^{*}+Q_{s}^{*}=1 \\
& L^{*}+U^{*}=N^{*}
\end{aligned}
$$




$$
\begin{aligned}
& A_{s}{ }^{*}+I_{s}{ }^{*}=Q_{s}{ }^{*} \\
& A_{d}{ }^{*}+I_{d}{ }^{*}=Q_{d}{ }^{*} .
\end{aligned}
$$

Condition (i) pins down the drug price function as in (9). Condition (ii) requires the drug market to clear. Conditions (iii) provide necessary and sufficient conditions for constant populations of workers and drug market participants. Conditions (iv) summarize the four population identities described in Section 2.

The model possesses a convenient recursive structure, which can be exploited to prove the existence of equilibrium and analyze its properties. As the wage rate $w$ is exogenously given, the equilibrium drug price $p^{*}$ is pinned down by (9) as elaborated in Proposition 1 . Then, (5) and (10d) together yield the equilibrium values of demand-side policies, $A_{d}{ }^{*}$ and $I_{d}{ }^{*}$. Next, substituting the equilibrium value of the drug price and the equilibrium population of drug demanders into the drug market equilibrium condition (3) gives the equilibrium population of active drug dealers $A_{s}{ }^{*}$. This expression can then be used in conjunction with (4) and (10c) to obtain the equilibrium populations of incarcerated and potential drug dealers, $I_{s}{ }^{*}$ and $Q_{s}{ }^{*}$, respectively. Finally, from (10a) and the expression for $Q_{s}{ }^{*}$, the equilibrium population of potential workers $N^{*}$ is obtained, which together with (10b) yields the equilibrium populations of employment and unemployment, $L^{*}$ and $U^{*}$. In summary, we have:

$$
\begin{aligned}
& A_{d}{ }^{*}=\left[\rho_{d} /\left(\rho_{d}+\tau_{d}\right)\right] Q_{d} \\
& I_{d}{ }^{*}=\left[\tau_{d} /\left(\rho_{d}+\tau_{d}\right)\right] Q_{d} . \\
& A_{s}{ }^{*}=\mathrm{D}\left(p^{*}, A_{d}{ }^{*}\right) \\
& I_{s}{ }^{*}=\left(\tau_{s} / \rho_{s}\right) A_{s}{ }^{*}, \\
& Q_{s}{ }^{*}=\left[\left(\rho_{s}+\tau_{s}\right) / \rho_{s}\right] A_{s}{ }^{*}, \\
& N^{*}=1-Q_{s}{ }^{*},
\end{aligned}
$$




$$
\begin{aligned}
& L^{*}=[\mu /(\delta+\mu)] N^{*}, \\
& U^{*}=[\delta /(\delta+\mu)] N^{*} .
\end{aligned}
$$

Accordingly, the community's aggregate income in equilibrium can be obtained,

$$
\Omega^{*}=\mathrm{w} L^{*}
$$

Figure 2 illustrates the equilibrium determination of the amount of drug trade, $A_{s .}$. The perfectly elastic supply of drugs is given by the price $p^{*}$ determined by (9) under the career choice rule. Where this intersects the downward-sloping drug demand given by Assumption 2 determines the amount of active trade in drugs as in (11c).

Proposition 2. (Steady-state equilibrium) Under Assumptions 1 and 2, a unique steady-state equilibrium exists.

The comparative static properties are obtained through examination of the population equations (11a)-(11h), the drug price offer function (9), and the community aggregate income equation (12). All factors in the labor market (including $\mathrm{w}, \mu$ and $\delta$ ) and the supply-side factors ( $\tau_{s}$ and $\rho_{s}$ ) in the drug market influence the steady-state equilibrium populations of active drug demanders/suppliers, potential drug dealers, formal sector employment and aggregate community income only through their effect on the equilibrium drug price. In this paper, we are most interested in the comparative statics with respect to two policy instruments, namely, the arrest rates for drug dealers and demanders, $\tau_{d}$ and $\tau_{s}$. While the two release rates, $\rho_{s}$ and $\rho_{d}$, are two other parameters of interest, their effects are simply the mirror image of the arrest rates.

An increase in the workers' wage (w) or matching rate $(\mu)$, or a reduction in the job separation rate $(\delta)$, raises the incentive for agents to participate in the formal job market. In equilibrium, the reward to drug dealing must rise in order to maintain the equality of value in the 
two careers. This leads to a higher drug price, but a lower populations of potential and active drug dealers, and greater employment and community income.

Increasing the arrest rate of drug demanders $\left(\tau_{d}\right)$ or decreasing the corresponding release rate $\left(\rho_{d}\right)$ reduces the number of active drug demanders (11a) so that the demand function in Figure 2 shifts to the left (11c). Since it does not affect the career choice, demand-side arrests have no effect on the drug price and as a result, the number of (potential and active) drug sellers must fall to maintain drug market equilibrium. This consequently leads to higher employment in the formal job sector and greater community income.

An increase in the supply-side arrest rate $\left(\tau_{s}\right)$ or a reduction in the corresponding release rate $\left(\rho_{s}\right)$ is a bit more complicated in its effects. There is, first, a direct incarceration effect. A higher arrest rate puts more drug dealers in jail, given the population of active dealers, as evidenced in (11d). The drug price that equates the two career choices must rise, and given the downward sloping demand, the number of active dealers $\left(A_{s}{ }^{*}\right)$ must fall, but the extent to which it falls depends on the form of the demand curve. We call this the drug-dealing replacement effect. Some number of newly incarcerated dealers are replaced by new entrants into the drug market, depending on the level of demand at the higher price. Thus the effect on the potential drug dealers $\left(Q_{s}{ }^{*}\right)$, which is the sum of active and incarcerated dealers, remains ambiguous, as does the effect on its complement, the number of people in the legitimate labor market $\left(N^{*}\right)$. The key is the elasticity of drug demand: in the limiting case of inelastic demand, a supply-side policy is completely self-defeating. The putative reduction in the drug trade caused by arresting dealers is exactly counterbalanced by a price rise sufficient to attract an equal number of new dealers out of the legitimate labor market. However, if demand is very elastic, the price rise needed to draw new dealers into the market in the face of greater incarceration risk is high 
enough to turn away most of the demand - in this case, the steady state population of workers may actually increase.

In summary, we have:

Proposition 3. (Comparative Statics) Under Assumptions 1 and 2, the unique steady-state equilibrium possesses the following properties:

(i) an increase in the workers' bargaining power, output or matching rate, or a reduction in the job separation rate, raises the drug price, legitimate employment and community income and lowers both active and potential drug dealers;

(ii) an increase in the arrest rate of drug demanders or a decrease in the corresponding release rate raises legitimate employment and community income and lowers active drug demanders as well as active and potential drug dealers without affecting the equilibrium price of drugs;

(iii) an increase in the supply-side arrest rate or a reduction in the corresponding release rate raises the drug price, lowers active drug dealers, and, as a result of the opposing direct incarceration and drug-dealing replacement effects, generates ambiguous effects on potential drug dealers, legitimate employment and community income.

These comparative static properties can be used to formulate and characterize the optimal drug policy to which we now turn.

\section{Optimal Drug Policy With a Balanced Local Government Budget}

The major concern of this paper lies in the effectiveness of supply- and demand-side drug policies, as represented by the two policy instruments - that is, the two arrest rates, $\tau_{s}$ and $\tau_{d}$. To compare the effectiveness of these two policies, it is necessary to further specify the cost structure of drug policies, the government budget constraint and its objective function.

We use the simplest possible specification for the costs of drug enforcement, assuming an identical unit cost of incarcerating a drug supplier and a drug demander, which is normalized to 
unity. Additionally, such law enforcement costs are assumed to be financed purely by lump-sum taxes, T, on workers. Thus, using (11e), the government budget constraint in steady-state equilibrium is written as:

$$
T^{*}=\tau_{d} Q_{d}+\tau_{s}\left[\left(\rho_{s}+\tau_{s}\right) / \rho_{s}\right] A_{s}^{*}
$$

In this case, each worker's wage needs to be modified,

$$
\mathrm{w}^{*}=\mathrm{w}-T^{*} / L^{*}
$$

whereas, from (11f) and (11g), the community's equilibrium aggregate income is then given by,

$$
\Omega^{*}=\mathrm{w}[\mu /(\delta+\mu)]\left(1-Q_{s}^{*}\right)-T^{*} .
$$

Among several possibilities, we consider three potential objectives that local governments may have. The first one is the reduction of illegal drug activity, $A_{s}$, in their communities. $^{12}$ The second is the reduction of the total population of criminals, $Q_{s}$. The third objective is to increase the legitimate income flow in the community, $\Omega{ }^{13}$ Note that the general form of drug demand described in Assumption 2 can not provide closed-form solutions for the optimal drug policy. We therefore consider two special cases of drug demand, linear and constant elasticity forms, to gauge the optimal arrest rates under the three objectives mentioned above. The implications for the design of optimal drug policy derived from these two special cases may provide some insights for the general case. The benchmark case features a linear drug

${ }^{12}$ For notational simplicity, we drop all superscript * that used to denote equilibrium values.

13 Alternatively, we may define the income flow as the gross domestic income. That is, $\Omega^{\prime}=$ $w L+(Y-w) F$. If we assume that each job can have one at most one worker, then $F=L$. That is, the number of matched firms is same as the number of employed workers. As a result, $\Omega^{\prime}=Y L$. Using wage income as the definition of income flow (i.e., $\Omega=\theta Y L$ as in (12)) is equivalent to assume absentee ownership of firms, whose profits are not spend locally. It is also reasonable to believe that local governments are also concerned about firms' profits if we adopt the gross domestic income as the definition of income flow. Nevertheless, the results of analysis based on both definitions are identical since $\omega$ is constant. 
demand schedule: $\mathrm{D}\left(p, A_{d}\right)=A_{d}-b p$, where $b>0$ is constant and exogenously given. The alternative is to consider a drug demand function with constant price elasticity: $\mathrm{D}(p)=A_{d} / p^{\eta}$, where $\eta>0$ is the price elasticity of drug demand, an exogenous constant. Since all cases considered here use the same approach and economic reasoning, we focus our discussion primarily on the case of linear drug demand under the first objective, while referring to others to the extent that they are of separate interest.

We write the tax per worker as a function of the number of drug suppliers, and the exogenous population of potential demanders using (11e), (11f) and (11g):

$$
\frac{\mathrm{T}}{\mathrm{L}}=\frac{\tau_{\mathrm{d}} \mathrm{Q}_{\mathrm{d}}+\tau_{\mathrm{s}}\left(\frac{\tau_{\mathrm{s}}+\rho_{\mathrm{s}}}{\rho_{\mathrm{s}}}\right) \mathrm{A}_{\mathrm{s}}}{\frac{\mu}{\mu+\delta}\left(1-\frac{\rho_{\mathrm{s}}+\tau_{\mathrm{s}}}{\rho_{\mathrm{s}}} \mathrm{A}_{\mathrm{s}}\right)}=\mathrm{t}\left(\mathrm{A}_{\mathrm{s}} ; \mathrm{Q}_{\mathrm{d}}, \rho_{\mathrm{s}}, \tau_{\mathrm{s}}, \rho_{\mathrm{d}}, \tau_{\mathrm{c}}\right)
$$

It is evident that the tax per worker is rising in $A_{s}$. Therefore, the career choice rule, replacing the wage with the after-tax wage, becomes a decreasing function of $A_{s}$,

$$
\mathrm{p}=\Pi\left(\mathrm{A}_{\mathrm{s}}\right)=\frac{\mu}{\mathrm{r}+\delta+\mu} \frac{\mathrm{r}+\rho_{\mathrm{s}}+\tau_{\mathrm{s}}}{\mathrm{r}+\rho_{\mathrm{s}}}[(\theta \mathrm{Y}-\mathrm{t}(\mathrm{As}))]
$$

This function is displayed in the southeast quadrant of Figure 3. The price/after-tax wage combination that equalizes the values for the two careers creates a downward sloping career choice (CC) locus. For any given arrest rate, a greater number of active dealers requires a higher tax per worker, which lowers the return from lawful employment and lowers the price necessary to equilibrate the two career values.

Under the linear demand specification, there is a choke price for drugs. Therefore, given the link between the wage and the price, there is a maximum wage at or above which all residents will choose the legitimate labor market: $w^{\max }=\frac{r+\delta+\mu}{\mu} \frac{r+\rho_{s}}{r+\rho_{s}+\tau_{s}} \frac{\rho_{d}}{\rho_{d}+\tau_{d}} \frac{Q_{d}}{b}$. Define the 
"relative wage" as: $R=\frac{w-t\left(A_{s}\right)}{w^{\max }}$. Then if $R \geq 1$, it implies the expected returns of workers always exceed or equal to that of drug dealers even without drug policy. Under these circumstances, the wage offers in the labor market are high enough to prevent people from being drug dealers, which is not interesting. For this reason we need only consider low-income neighborhoods such that,

Assumption 3. $R<1$.

Under this assumption we can substitute the price in (17) into the linear demand function to produce an equilibrium drug (ED) correspondence as a function of the population of active dealers,

$$
\mathrm{D}=\left[1-\mathrm{R}\left(\mathrm{A}_{\mathrm{s}} ; \tau_{\mathrm{d}}, \tau_{\mathrm{s}}\right)\right] \frac{\rho_{\mathrm{d}}}{\rho_{\mathrm{d}}+\tau_{\mathrm{d}}} \mathrm{Q}_{\mathrm{d}}=\Delta\left(\mathrm{A}_{\mathrm{s}}\right)
$$

That the ED locus is upward sloping is clear from the fact that $\mathrm{R}$ is negatively related to $A_{s}$, and from the northeast quadrant of Figure 3, which traces out the locus of points in $\left(A_{s}, D\right)$ space that are congruent with both the career choice rule (i.e., the $\mathrm{CC}$ locus in the southeast quadrant) and the demand function (i.e., the $D\left(p, A_{d}\right)$ schedule in the northwest quadrant). Should there be a downward shift in the demand curve or an upward shift in the CC locus, the ED locus will shift downward. The equilibrium amount of drug activity is pinned down where the ED locus crosses the $45^{\circ}$ line, which equates supply $\left(S=A_{S}\right)$ and demand ( $D$ specified as in (18) above):

$$
\mathrm{A}_{\mathrm{s}}=\Delta\left(\mathrm{A}_{\mathrm{s}}\right)=\left[1-\mathrm{R}\left(\mathrm{A}_{\mathrm{s}} ; \tau_{\mathrm{d}}, \tau_{\mathrm{s}}\right)\right] \frac{\rho_{\mathrm{d}}}{\rho_{\mathrm{d}}+\tau_{\mathrm{d}}} \mathrm{Q}_{\mathrm{d}}
$$

This leads to a unique fixed point $\mathrm{A}_{\mathrm{s}}=\mathrm{A}_{\mathrm{s}}\left(\tau_{\mathrm{d}}, \tau_{\mathrm{s}} ; \rho_{\mathrm{d}}, \mathrm{Q}_{\mathrm{d}}\right)$. 
We can now turn to the government's policy in the face of the various objectives it might have. Given the first objective, a local government attempts to lower $A_{s}$ given in (19). Examine first the effects of a demand-side policy, an increase in the demand arrest rate $\left(\tau_{d}\right)$ that decreases the population of active demanders $\left(A_{d}\right)$ as suggested by (11a). From Figure 3 and the analysis above, there will be more than one effect shifting the ED loci. The first will be a shift down in the demand curve $\mathrm{D}\left(\mathrm{p}, \mathrm{A}_{\mathrm{d}}\right)$ in the northwest quadrant of Figure 3, which will on its own cause a lowering of the ED locus, as implied by (17). However, equation (18) indicates there are also a number of effects that work on the $\mathrm{CC}$ locus through the effects on the tax per worker. On the one hand, the increase in $\tau_{\mathrm{d}}$ directly causes an increase in enforcement costs $(T)$. On the other, as a consequence of the downward shift in the ED locus in response to the demand shift, the steadystate level of drug dealers declines (see the northeast quadrant of Figure 3). This both lowers the aggregate cost $(T)$ and raises the number of legitimate labor-market participants $(L)$ over whom the cost can be spread. The net effect of these actions can cause either a rise or fall in the per worker tax, T/L. In the worst-case scenario where the former direct effect dominates, it results in a rise in $\mathrm{T} / \mathrm{L}$ and the fall in the after-tax wage lowers the price necessary to equalize the two career values. In the diagram this causes a shift toward the origin of the CC locus and hence an upward shift of the ED locus. The respective shifts in the demand curve and the CC locus move the ED locus in opposite directions and so have a generally ambiguous effect on the amount of drug market activity (measured by $\mathrm{D}=\mathrm{S}=\mathrm{A}_{\mathrm{s}}$ ). Nevertheless, it is very plausible that the per worker tax effect is secondary and hence the demand shift is likely to dominate, leading to a net reduction in active drug trade.

Supply-side policy has three effects, all of which work on the CC locus without affecting the demand schedule. First, the increase in $\tau_{\mathrm{s}}$ directly increases the drug price that is necessary to 
keep the two career values equal. This pushes the $\mathrm{CC}$ curve away from the origin and shifts the ED locus downward. As before, this would lower the amount of the drug activity in the community only to the extent that demand is not driven off by the higher prices. There is therefore an increase in the cost $(\mathrm{T})$ of pursuing the policy. Moreover, the drug-dealing replacement effect insures that with the net decrease in $\mathrm{L}$, the tax per worker will be greater. This latter change in turn decreases the price-wage gap, resulting in a downward shift in the CC locus and an increase the quantity of active drug trade. Thus, the net effect on drug activity from all channels remains ambiguous.

The superiority of one policy or the other can never be guaranteed for all parameter values, so there cannot be a definitive statement that demand-side policy is best at reducing drug activity. One of the key parameters is the slope of the drug demand function. It is important to note that in the absence of a first-order demand deterrence effect, the supply-side arrest policy only works through its influence on career choice. Should the demand schedule be rather inelastic (i.e., $D\left(p, A_{d}\right)$ is flat in $(p, D)$ space as plotted in the northwest quadrant of Figure 3$)$, the resulting shift in the $\mathrm{CC}$ locus is negligible, thereby making the supply-side policy less effective. Indeed, for inelastic demand curves, not only is the direct incarceration effect of arresting demanders stronger, but so is the drug-dealing replacement effect under supply-side policy. These reinforce previous arguments: the less sensitive drug demand is to price, the more appropriate will demand policy be. ${ }^{14}$ More generally, we can compare these two drug policies in the context of tax incidence under a constant law enforcement spending, $T$. While demand arrests have a direct demand deterrence effect, and supply arrests reduce the drug trade via their

14 It is not our intention to draw any formal conclusion with respect to the price elasticity of drug demand, as its values vary along the linear demand schedule. We will return to this issue later under the consideration of a constant elasticity demand function. 
impact on career choice (through the increase in $p$ ), the demand-side policy increases legitimate employment while the supply-side policy reduces it, due to the drug-dealing replacement effect. These labor-market effects make demand-side policy under many scenarios superior to supplyside policy. Thus, we can summarize the main results as follows:

Proposition 4. (Optimal Drug Policy) Under Assumptions 1-3, a linear drug demand schedule and a community government's objective to minimize the active drug trade, the effectiveness of drug policies is characterized as follows:

(i) demander arrests have a direct effect on drug trade via deterrence of demand, whereas and supplier arrests reduce drug trade via the choice of careers;

(ii) demand-side policy increases legitimate employment whereas the supply-side policy reduces it, making demand policy more effective under constant law enforcement spending;

(iii) the less sensitive drug demand is to price, the more appropriate will demand policy be.

We turn next to the second objective where a local government minimizes potential drug activity, as measured by the population of potential dealers:

$$
\mathrm{Q}_{\mathrm{s}}=\frac{\rho_{\mathrm{s}}+\tau_{\mathrm{s}}}{\rho_{\mathrm{s}}}\left[1-\mathrm{R}\left(\mathrm{A}_{\mathrm{s}} ; \tau_{\mathrm{d}}, \tau_{\mathrm{s}}\right)\right] \frac{\rho_{\mathrm{d}}}{\rho_{\mathrm{d}}+\tau_{\mathrm{d}}} \mathrm{Q}_{\mathrm{d}}
$$

With this objective, the case for demand-side policy becomes even stronger. This is because the previous discussion of the drug-dealing replacement effect suggests that there is an unambiguously positive impact on $\mathrm{Q}_{\mathrm{s}}$ from increasing the supplier arrest rate, while the tax per worker increases in the same manner as before (which can be seen by comparing (20) with (19)).

With regard to the third objective, a community government maximizes its aggregate income,

$$
\Omega=\frac{w \mu}{\mu+\delta}\left\{1-\frac{\rho_{s}+\tau_{s}}{\rho_{s}}\left[1-R\left(A_{s} ; \tau_{d}, \tau_{s}\right)\right] \frac{\rho_{d}}{\rho_{d}+\tau_{d}} Q_{d}\right\}-T\left(A_{s} ; \tau_{d}, \tau_{s}\right)
$$


Comparing (21) with (20), we note that minimization of potential drug activity and maximization of aggregate community income only differs in the negative law enforcement spending effect.

It remains to examine the optimal drug policy under the alternative, constant-elasticity drug demand schedule. In this case, the equilibrium drug activity measured by active dealers becomes:

$$
A_{s}=\left[\left(\frac{r+\mu+\delta}{\mu}\right)\left(\frac{1}{\theta Y-t\left(A_{s} ; \tau_{d}, \tau_{s}\right)}\right)\left(\frac{r+\rho_{s}}{r+\rho_{s}+\tau_{s}}\right)\right]^{\eta} \frac{\rho_{d}}{\rho_{d}+\tau_{d}} Q_{d}
$$

It turns out that the qualitative effects of policy can be carried over to this case, although the quantitative effects are naturally different. More specifically, if $\eta<1$, the threat from demand arrests is more effective and hence the demand-side policy is preferred under the first local government objective. That is, if the community suffer a severe drug problem so that drug demand is inelastic to price variations, the drug demand policy is more advantageous - it conforms a well-known property of the optimal taxation literature in a very different context. The analyses regarding to the other two objectives are parallel to those discussed above and hence omitted without further elaboration for the interest of space.

Proposition 5. (Optimal Drug Policy) Under Assumptions 1-3, the effectiveness of drug policies is characterized as follows.

(i) Under a linear drug demand schedule, and when the community government's objective is to minimize the potential drug trade, the positive drug-dealing replacement effect is stronger and the demand-side policy is more effective than the supply-side policy;

(ii) Under a linear drug demand schedule, and when a community government's objective is to maximize the community income, the relative effectiveness of the demand and supplyside policies is the same as when a community government's objective is to minimize the potential drug trade, as long as the law enforcement effect remains constant;

(iii) Under a constant elasticity drug demand schedule, the lower the demand elasticity, the more advantageous will the demand policy be.

To illustrate, we provide numerical examples that compute the optimal flow rates of 
demand and supply arrests, under linear and constant-elasticity drug demand schedules. ${ }^{15}$

Example 1. (Linear Drug Demand) Let $D=A_{d}-0.0005$ p. Moreover, let: $w=5 ; r=7.5 \% ; \delta$ $=0.002$ and $\mu=0.03$ (to produce an unemployment rate in the legitimate labor market at about $6.5 \%$ ); $\rho_{\mathrm{s}}=\rho_{\mathrm{d}}=0.8$ (to maintain about $80 \%$ active drug traders); and, $\mathrm{Q}_{\mathrm{d}}=0.25$ (which ensures a positive price). The unique steady-state equilibrium is obtained, with $\mathrm{p}=1.54, \mathrm{~A}_{\mathrm{s}}=0.22, \mathrm{Q}_{\mathrm{s}}=$ $0.25, \mathrm{~L}=0.70, \mathrm{U}=0.047$, and $\Omega=3.42$. When the government objective is to minimize the active drug supplier, the optimal flow arrest rate for drug demanders is 21.56 and that for drug suppliers is 1.78. This suggests an interior solution for using both drug policies, though it is much more inclined toward the demand-side arrest policy.

Example 2. (Constant-Elasticity Drug Demand) Let $D=A_{d} / p^{0.005}$, where the price elasticity of drug demand is selected such that the equilibrium is identical that obtained in Example 1, under the same parameters as in the previous example: $\mathrm{w}=5, \mathrm{r}=7.5 \%, \delta=0.002, \mu=0.03, \rho_{\mathrm{s}}=$ $\rho_{\mathrm{d}}=0.8$, and $\mathrm{Q}_{\mathrm{d}}=0.25$. Yet, when the government objective is to minimize the active drug supplier, the optimal flow arrest rate for drug demanders is now infinity and that for drug suppliers is now at the lower bound (zero). This suggests a complete elimination of supply-side arrests, while employing demand-side arrests at highest possible frequency to prevent outside drug demanders from entering the local drug market.

\section{Extensions}

In this section, we extend the basic model in four interesting directions - to allow for the neighborhood externality from drug selling, to permit multi-unit drug dealing, to incorporate utility costs of incarceration and to consider social costs of drugs on workers.

\footnotetext{
${ }^{15}$ Although we parameterize within plausible ranges, it is not a formal calibration without complete drug trade data.
} 


\section{Neighborhood Externality}

In this subsection we illustrate how to extend the model to include the neighborhood externality, which is widely believed an important factor in the drug market. One way to do this is to augment the value function for drug dealers to include a term that shifts the value according to the number of dealers that are in the community. This can be a positive shift if the stigma from engaging in illegal activity is lower, or, it can be negative if there are crowding-out effects such that the unit cost of doing business increases with the number of participants. ${ }^{16}$ To incorporate both possibilities, we simply rewrite the value function of an active drug dealer as:

$$
r J_{A s}=p A_{s}^{\gamma}+\tau_{s}\left(J_{I s}-J_{A s}\right)
$$

That is, the level of utility received by active drug dealers is the drug income weighted by $A_{s}^{\gamma}$, where $\gamma$ could be positive or negative, as argued above.

Interestingly, career choice under this extension leads to a drug price function that depends directly on the population of active drug dealers:

$$
p\left(A_{s} ; w, \mu, \delta, r, \tau_{s}, \rho_{s}\right)=\frac{\mu}{r+\delta+\mu} \frac{r+\rho_{s}+\tau_{s}}{r+\rho_{s}} w A_{s}^{-\gamma},
$$

This together with the drug market equilibrium condition under linear demand schedule implies:

$$
A_{s}=\frac{\rho_{d}}{\rho_{d}+\tau_{d}}-b \frac{\mu}{r+\delta+\mu} \frac{r+\rho_{s}+\tau_{s}}{r+\rho_{s}} w A_{s}^{-\gamma}
$$

Thus, when drug dealers face a negative neighborhood externality, all of our previous analyses remain qualitatively unchanged. Should such externality be positive to drug dealers, it is possible that the implications of the drug arrest policies are reversed.

\section{Multi-unit Drug Dealing}

In our benchmark model, drug dealers are identical ex ante and each possesses exact one

\footnotetext{
${ }^{16}$ The effects of stigma and social interactions have been discussed extensively in the literature of crime; for example, see Sah (1991) and Glaeser, Sacerdote and Scheinkman (1996), respectively.
} 
unit of drug at a point in time. While this greatly simplifies the analysis, one may wonder if the consideration of high-volume drug dealing as a more severe crime may alter the relative effectiveness of demand-side to supply-side policies. To address this concern, we consider two types of drug-selling activities: a low-volume drug dealer (type L) supplies one unit of drug but a high-volume dealer (type $\mathrm{H}$ ) supplies $\mathrm{q}>1$ units. While the structure and behavior of lowvolume drug trade are exactly the same as previously described, incarcerated high-volume dealers are subject to a more severe conviction, reflected by a lower release rate $\rho_{s}^{H}=\alpha \rho_{s}<\rho_{s}=$ $\rho_{s}^{L}$. As in some other models of criminal behavior, there is a "hide-in-the-crowd" effect, in the sense that the effective arrest rate is lower when the number of criminals is large. Denote the fraction of active dealers as $\beta$ (to be determined endogenously in equilibrium). By normalizing $\tau_{s}^{L}=\tau_{s}$, the effective arrest rate facing each high-volume dealer can be specified as: $\tau_{s}^{H}=[(1-$ $\beta) / \beta] \tau_{s}$, i.e., the effective arrest rate is inversely related to the relative size of the population. Thus, this creates another dimension to the career choice decision facing each resident (legitimate job, low-volume drug dealing and high-volume drug dealing) ${ }^{17}$ and the career choice rule becomes:

$$
J_{U}=J_{A s}{ }^{L}=J_{A s}{ }^{H}>0,
$$

where $J_{A s}{ }^{L}$ is as in (7c) and

$$
J_{A s}^{H}=\frac{r+\alpha \rho_{s}}{r+\alpha \rho_{s}+\tau_{s}(1-\beta) / \beta} \frac{p q}{r} .
$$

The two equations in (26) jointly solves the drug price offer function, same as equation (9), and the equilibrium fraction of high-volume active drug dealers:

${ }^{17}$ This type of career choice is analogous to Helsley and Strange (2001) where in the second stage of their game-theoretic model, criminals choose the severity of the crimes to commit. 


$$
\beta=\frac{1}{1+\left(r+\alpha \rho_{s}\right)\left[(q-1) / \tau_{s}+q /\left(r+\rho_{s}\right)\right.} .
$$

Straightforward differentiation shows that the additional penalty for high-volume drug dealing (higher $\alpha$ ) discourages such an activity. Yet, due to the hide-in-the-crowd effect, the overall measure of the arrest rate $\left(\tau_{s}\right)$ generates a disproportionate deterrent effect on low-volume drug dealing, thereby resulting in a higher fraction of high-volume active dealers. If deterrence of more severe drug activities is an objective of the local government, the above analysis suggests an additional disadvantage associated with the supply-side drug policy.

\section{Utility Cost of Incarceration}

So far, the specification of career choice forces equal expected values of entering the formal labor sector and the illegal drug market in equilibrium, as indicated by (8). One limitation that is imposed in those value functions is that the cost of incarceration and unemployment are both zero. It's likely that the former creates a lower level of utility than the latter. Thus, there may be a utility cost, c, incurred by incarcerated drug dealers. That is, letting $J_{A s}$ denote the "gross" value facing a potential drug dealer, the corresponding "net" value can be written as $J_{A S}-$ c. Accordingly, the career choice rule implies:

$$
J_{U}=J_{A s}-c>0
$$

It is easily shown that the drug price function becomes:

$$
p\left(w, \mu, \delta, r, \tau_{s}, \rho_{s}\right)=\frac{\mu}{r+\delta+\mu} \frac{r+\rho_{s}+\tau_{s}}{r+\rho_{s}} w+c,
$$

Similar results can be obtained and in addition the incarceration cost may be regarded as a policy instrument, which captures, for example, the cost of imprisonment. An increase in this cost raises the equilibrium price and lowers drug demand as well as active drug supply. The countervailing power of the 
drug-dealing replacement effect is lower as well. If there is an otherwise costless increase in prison disutility then the effects of a rise in c are unambiguously good for any objective.

\section{Social Costs of Drugs}

In previous sections, we focus on a "small open" community of drug in which the social costs of drug is ignored throughout. Should there be such costs, measured by $\psi A_{s}$ with $\psi>0$, we can then rewrite a worker's net flow value accrued from a successful match as $\theta Y-\psi A_{s}$. Career choice yields,

$$
p\left(w, \mu, \delta, r, \tau_{s}, \rho_{s}\right)=\frac{\mu}{r+\delta+\mu} \frac{r+\rho_{s}+\tau_{s}}{r+\rho_{s}}\left(w-\psi A_{s}\right)
$$

and drug market equilibrium under linear demand schedule gives:

$$
A_{s}=\left(1-b \psi \frac{\mu}{r+\delta+\mu} \frac{r+\rho_{s}+\tau_{s}}{r+\rho_{s}}\right)^{-1}\left[\frac{\rho_{d}}{\rho_{d}+\tau_{d}}-b \frac{\mu}{r+\delta+\mu} \frac{r+\rho_{s}+\tau_{s}}{r+\rho_{s}} w\right]
$$

Again, our main results remain qualitatively valid as long as $\frac{b \psi \mu}{r+\delta+\mu} \frac{r+\rho_{s}+\tau_{s}}{r+\rho_{s}}<1$, which is like to hold if $\psi$ is sufficiently small.

\section{Concluding Remarks}

We have developed an endogenous career choice model to examine the welfare implications of both demand- and supply-side drug policies, from the point of view of a lowincome community that is the site of the drug market. Our emphasis has been on inferences that are available about the effectiveness of the two policies under different types of demand functions and government objectives. Under a linear drug demand schedule, the demand arrest policy is likely to be more effective due to asymmetric effects on the negotiated drug price and the legitimate labor employment, especially when both arrest policies yield similar law enforcement spending effects. This asymmetry is absent in conventional canonical Walrasian models without market frictions. Compared to the objective of minimizing active drug selling, deterrence of potential drug dealer entry results in a relatively lower optimal supply arrest rate 
while promotion of community's aggregate income leads to lower levels of both optimal drug arrest policies. Under a constant-elasticity drug demand schedule, the main conclusions concerning various local government objectives remain valid. However, the price elasticity of drug demand is a crucial determinant for comparing the effectiveness of demand and supply policies. In a society with severe drug problems so that drug demand is inelastic to price changes, the demand-side arrest policy is more preferred.

Despite providing a number of useful insights for drug policy recommendations, our model of course has its limitations. Among the most prominent is the lack of human capital or the ability to acquire it. Our framework shunts much of the labor market framework into the background, so that even if we allowed productivity and wages to depend on human capital the basic results would not change. An interesting extension would be to allow human capital to have positive wage effects and positive neighborhood externalities. The latter channel is likely to cause residents to under-invest in human capital, thus driving "too many" into the drug trade. In this case, not only will the welfare implications of the demand and drug arrest policies be different, but there may be a positive role for policies to prevent recidivism, ${ }^{18}$ or even a minimum wage policy, to play in correcting the incentive problem associated with human capital investment. Another potentially interesting extension is to evaluate the consequences of a "legalized" drug market using our modified framework that allows for multi-unit sales. In this case, limited quantities of drugs are permitted for trade with an ad valorem tax, whereas excessive sales are subject to arrest and conviction. It is then possible to examine the effectiveness of this sin tax relative to direct demand-side and supply-side arrest policies.

\footnotetext{
${ }^{18}$ One may follow the crime and poverty framework developed by Huang, Laing and Wang (2002) to model how prison education may affect individual's incentive to start a new life.
} 


\section{References}

Becker, G. S. (1968), “Crime and Punishment: An Economic Approach,” Journal of Political Economy 76 (2), 169-217.

Chaloupka, F., M. Grossman, and J. Tauras (1999) “The Demand for Cocaine and Marijuana by Youth" in The Economic Analysis of Substance Use and Abuse. (ed. Chaloupka, et al) Chicago: TheUniversity of Chicago Press, pp. 133-155.

Coulson, E., D. Laing and P. Wang (2001), “Spatial Mismatch in Search Equilibrium,” Journal of Labor Economics 19 (4), 949-972.

Diamond, P. A. (1982), “Wage Determination and Efficiency in Search Equilibrium,” Review of Economic Studies 49 (2), 217-227.

Freeman, S., J. Grogger and J. Sonstelie (1996), “The Spatial Concentration of Crime,” Journal of Urban Economics 40 (2), 216-231.

Glaeser, E., B. Sacerdote and J. Scheinkman (1996), “Crime and Social Interaction,” Quarterly Journal of Economic 111 (2), 507-548.

Helsley, R. and W. Strange (2001), "Mixed Markets and Crime," Working Paper, University of Toronto.

Huang, C., D. Laing and P. Wang (2001), "Crime and Poverty," Working Paper, Penn State University.

Laing, D., T. Palivos, and P. Wang (1995), "Learning, Matching and Growth," Review of Economic Studies 62 (1), 115-129. 
Levitt, S. and S. A. Venkatesh (1998) "An Economic Analysis of a Drug-Selling Gang's Finances" Quarterly Journal of Economics 115 (4), 755-790

Lucas, R. E., Jr. (1988), “On the Mechanics of Economic Development,” Journal of Monetary Economics 22 (1), 3-42.

Meares, T. (1998), "Social Organization and Drug Law Enforcement," American Criminal Law Review.

National Office of Drug Control Policy (1999), Drug and Crime Facts.

Rosen, J. (1997), “The Social Police,” The New Yorker, October 20 \& 27, 171-181.

Sah, R. K. (1991), “Social Osmosis and Patterns of Crime,” Journal of Political Economy 99 (6), 1272-1295. 


\section{Chart 1}

The Structure of the Economy

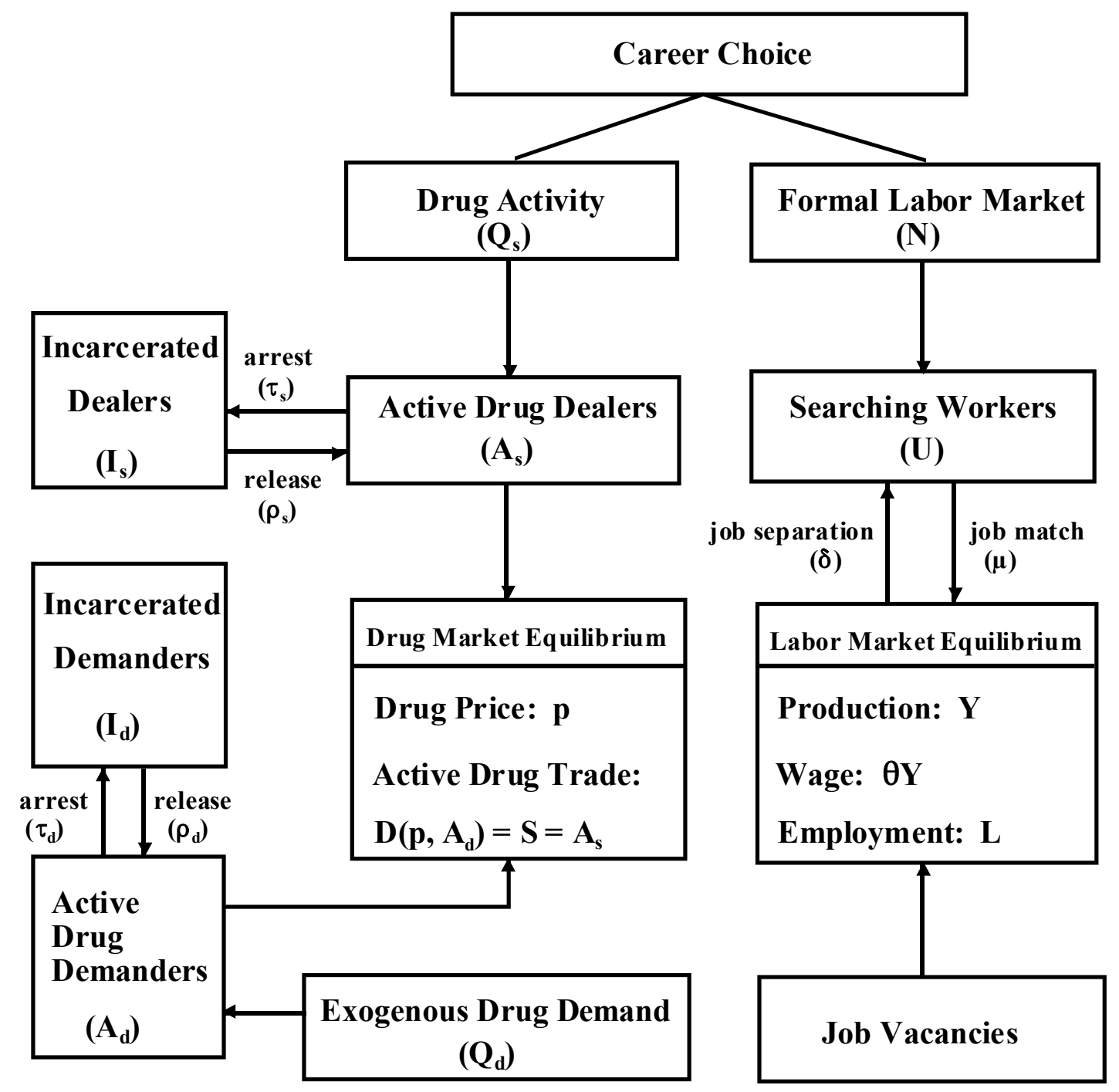


Figure 1

Supply-side Arrests as a Percentage of Total Arrests

by All U.S. Law Enforcement Agencies (1988-97)

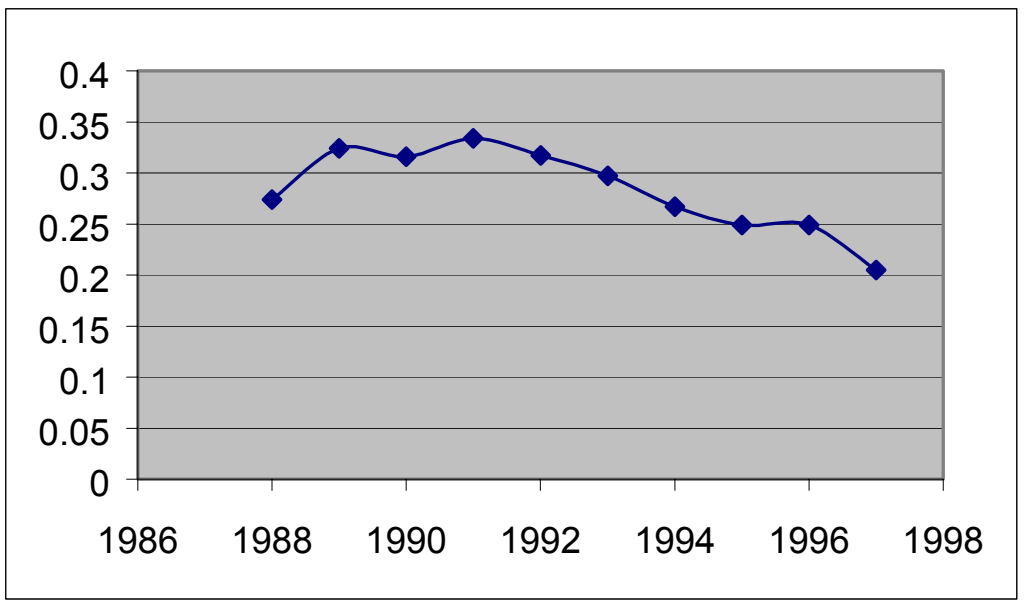

Figure 2

Steady-State Equilibrium

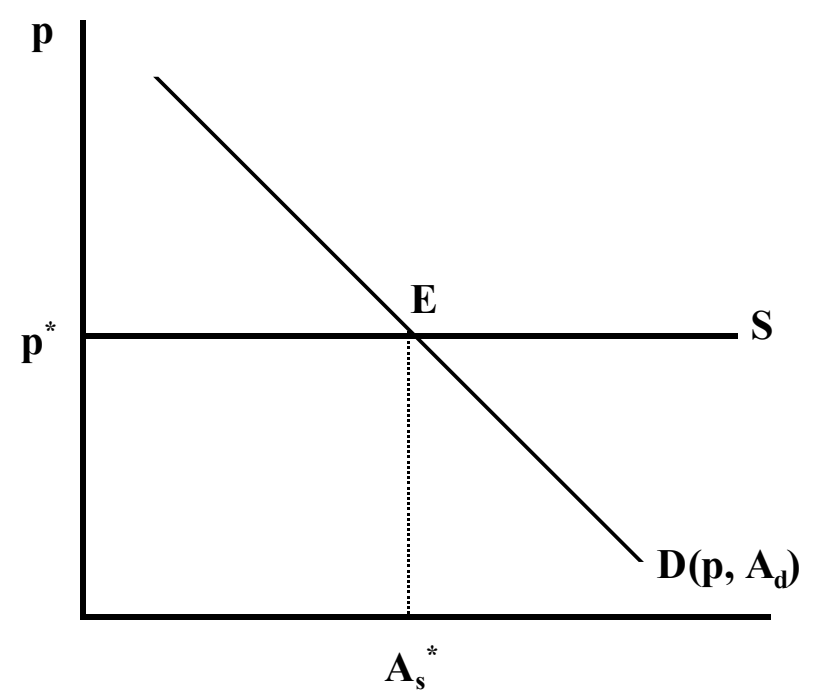


Figure 3

Steady-State Equilibrium with Balanced Government Budget and Linear Drug Demand

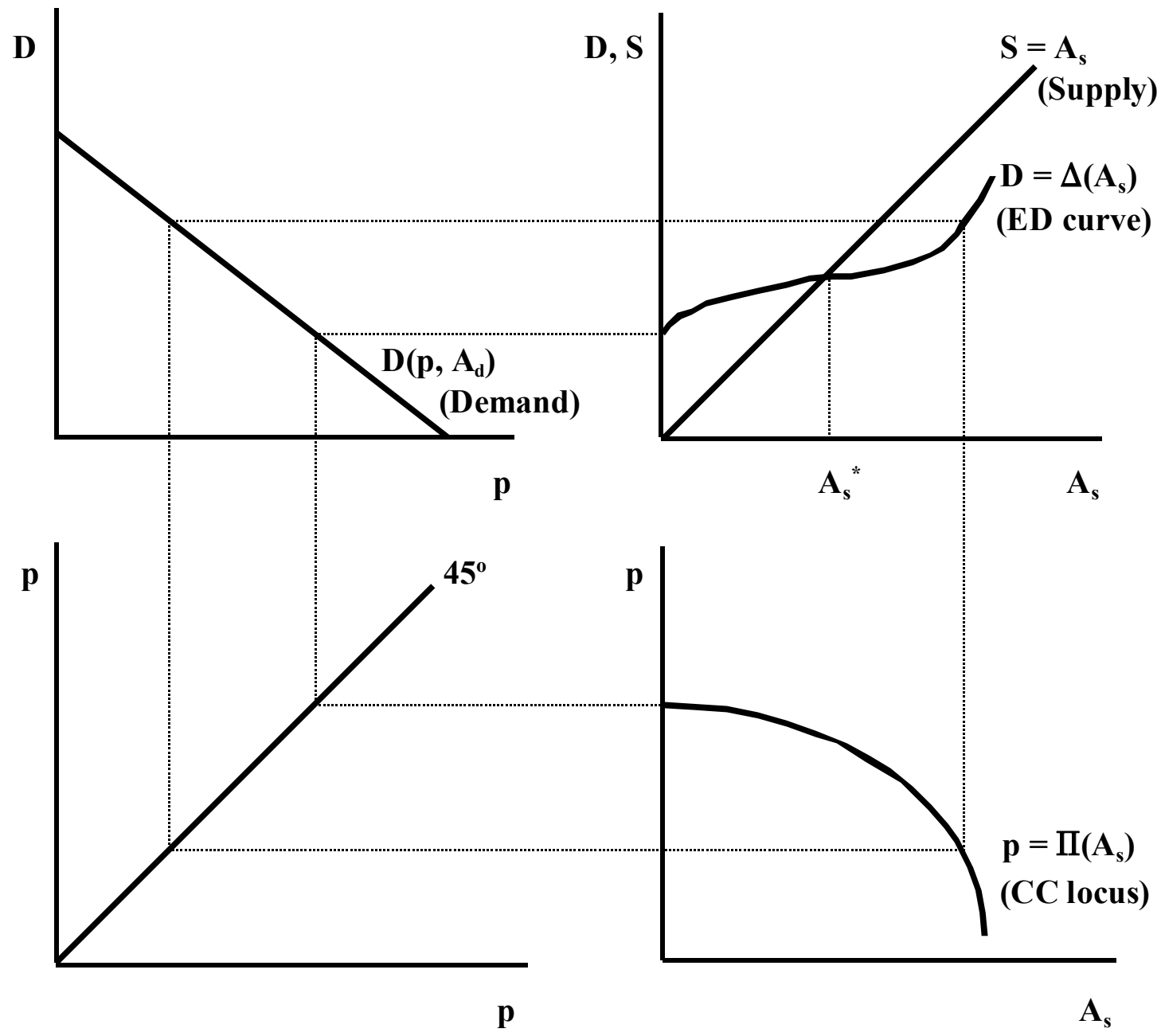

